\title{
ARTICLE
}

\section{Study for shielding efficiency of evacuation facilities in nuclear emergency}

\author{
Tomomi Oguri ${ }^{\mathrm{a}^{*}}$, Shogo Takahara ${ }^{\mathrm{b}}$, Masanori Kimura ${ }^{\mathrm{b}}$ and Toshimitsu Homma ${ }^{\mathrm{b}}$ \\ ${ }^{a}$ Visible Information Center, Inc.,440 Muramatsu, Tokai-mura, Naka-gun,Ibaraki-ken, 319-1112, Japan ; Japan Atomic Energy \\ Agency, 2-4 Shirakata, Tokai-mura, Naka-gun, Ibaraki-ken, 319-1195, Japan
}

\begin{abstract}
Sheltering is one of the protective actions to reduce external exposures from both the radioactive plume and the deposited radionuclides in a nuclear emergency. The aim of the present study is to provide the data of characteristics of evacuation facilities regarding building materials and structures, and preliminary estimates of shielding efficiency for the use of emergency planning. To achieve this aim, surveys were performed on the evacuation facilities actually used in Japan. In addition, for air submersion and deposited radionuclides, the shielding factors were calculated based on the survey results. The findings indicate that the shielding factors for the radiation due to air submersion were almost within the range of the previous works. The shielding factors, which were calculated with considerations of the radionuclides deposited only on the ground surface, were greater than those of the previous works. To explain the differences between the present study and previous works, an evaluation should be needed taking into account contributions of contaminated roofs.
\end{abstract}

Keywords: nuclear emergency preparedness; sheltering; reduction efficiency; shielding factor; Monte Carlo

\section{Introduction}

Sheltering is one of the planned protective actions to reduce external exposure from both the radioactive plume and the deposited radionuclides. In a nuclear emergency, prompt actions are desired before or immediately after a release of radioactive materials into the environment in order to implement realistic and efficient sheltering. Therefore a proactive choice of adequate facilities is needed from a viewpoint of capacity and location, as well as efficiency in reducing radiation exposure. Although evacuation facilities are prepared in the Prefectural Regional Emergency Prevention Plan (PREPP), their shielding efficiencies have not been evaluated. The aim of the present study is to provide the data of materials and structures of evacuation facilities, and preliminary estimates of shielding factors for the facilities. To achieve this aim, the surveys were performed for the evacuation facilities actually used in a PREPP of Shimane prefecture. In addition, shielding factors were calculated. This factor is defined as the ratio of air kerma indoors to that outdoors as follows;

$$
S f=\frac{K_{\text {in }}}{K_{\text {out }}}
$$

where $S f$ is the shielding factor; $K_{\text {in }}$ is the air kerma indoors due to the radiation from deposited radionuclides on the ground surface or radioactive plume; $K_{\text {out }}$ is the air kerma at a height of $1 \mathrm{~m}$ above the ground in open field.

\section{Methods}

\subsection{Survey on the characteristics of evacuation facilities}

The surveys on building materials and structures were performed for 12 evacuation facilities with 228 rooms listed in PREPP of Shimane prefecture based on the design drawings. These facilities are used as educational facilities under normal conditions. The type of these buildings is a multistory structure which comprises approximately the same-size cuboid rooms.

The results of surveys are shown in Table $\mathbf{1}$ and Table 2. The thickness and density of floors, walls, roofs and windows were also surveyed. From these data, mass thicknesses were obtained as the product of the thickness and the density of the materials. The structure of facilities was characterized in terms of floor-areas, floor-level, ceiling-heights and window-areas. Window-areas were given as the ratio of the window-area to the area of the corresponding outer wall.

\footnotetext{
* Corresponding author. Email: oguri@vic.co.jp 
Table 1. Mass thickness of structures of the facilities.

\begin{tabular}{ccccc}
\hline & Floor & Wall*1 & Roof*2 & Window \\
\hline $\begin{array}{c}\text { Mass thickness } \\
\left(\mathrm{g} / \mathrm{cm}^{2}\right)\end{array}$ & $28 \pm 8$ & $47 \pm 7$ & $28 \pm 8$ & $1.4 \pm 0.8$ \\
\hline 1.
\end{tabular}

${ }^{*}$ The value is expressed as the sum of outer walls and inner walls.

${ }^{* 2}$ The value is expressed as the sum of ceilings and roofs.

Table 2. The structural characteristics of each room for the facilities.

\begin{tabular}{cccc}
\hline Floor-area & Floor-level & Ceiling-height & Window-area \\
\hline $70 \pm 17 \mathrm{~m}^{2}$ & $50 \pm 14 \mathrm{~cm}$ & $379 \pm 13 \mathrm{~cm}$ & $44 \pm 14 \%$ \\
\hline
\end{tabular}

\subsection{Calculation of the shielding factor}

\subsubsection{Calculation method}

As shown Eq. (1), the shielding factors were obtained as the ratio of air kerma indoors to that outdoors. The air kerma inside and outside of the shelter were calculated by MCNP5 (Monte Carlo calculation code) [1] with ENDF/B-VI Release 8 cross section data [2]. For scoring photon fluxes, point detectors were applied. In addition, the calculations of the air kerma was made on the condition that statistical standard deviations are below 5 per cent.

\subsubsection{Calculation geometry}

Figure 1 shows the cross-sectional view of the building used in the calculations. A hypothetical building used in the present study was a single-story concrete building and the value of $2.1 \mathrm{~g} / \mathrm{cm}^{3}$ was adopted for the density of concrete. The structures and mass thickness were defined as the average values of the survey results on the actual facilities. In addition, the hypothetical building has windows, whose size was determined by the average value of the fraction surveyed.

For the calculations of the air kerma indoors, six detectors were defined inside the hypothetical building. The detectors were located at the center of the room and close to windows at heights of 0.25 and $1 \mathrm{~m}$ above the floor. The detectors of window side were located at 0.5 $\mathrm{m}$ from the inner wall. The calculation of the outside air kerma was made for the geometry without building. The detector was located at a height of $1 \mathrm{~m}$ above the ground surface.

\subsubsection{Photon source}

The calculations of shielding factors were performed for submersion in a contaminated atmospheric cloud (i.e. air submersion) and deposited radionuclides. The isotropic photons were emitted from the source points with mono-energies in the range from 0.1 to $1.5 \mathrm{MeV}$. This range was determined based on the energy of photons due to radionuclides including radioactive plume, i.e. noble gas, iodine, and cesiums, etc.

In the simulation for the air submersion, photon sources were located uniformly inside a half-sphere above the ground with a radius of $600 \mathrm{~m}$. For the deposited radionuclides, photon sources were placed only on the ground surface uniformly with a radius of $400 \mathrm{~m}$ from the building. Figure 2 shows a positional relationship of the building and the two source regions. The simulations were separately performed for each source region.

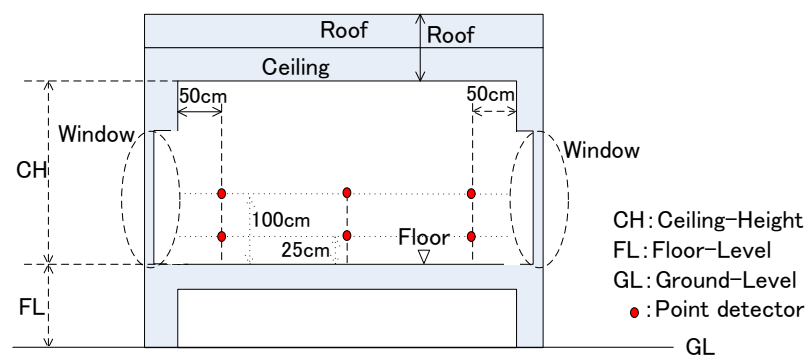

Figure 1. A hypothetical single-story building used for the calculations of shielding factors.

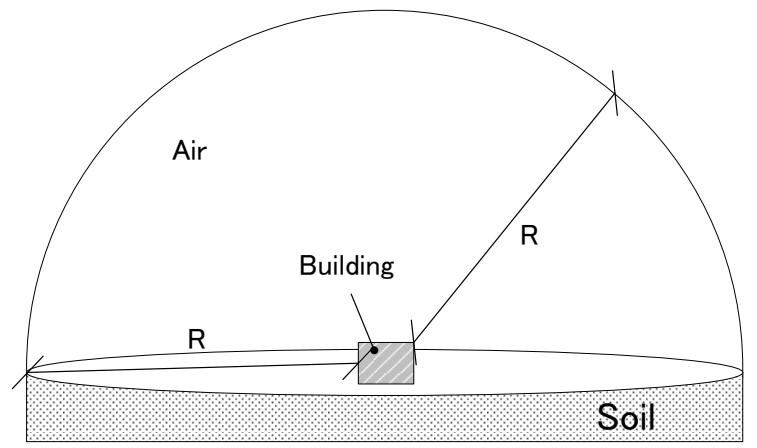

R: Up to $600 \mathrm{~m}$ (Air Submersion)

Up to $400 \mathrm{~m}$ (Deposited radionuclides)

Figure 2. Geometry for air kerma calculations by Monte Carlo method.

\section{Result and discussions}

\subsection{Shielding factors for the facilities}

Table 3 shows the result of shielding factors of the various locations in the room for the photon energy of $0.6 \mathrm{MeV}$, which corresponds to the energy of photons from ${ }^{137} \mathrm{Cs}$. The shielding factors for air submersion do not indicate the significant differences between the different heights of detectors. For deposited radionuclides, however, the shielding factors located at the height of $1.0 \mathrm{~m}$ were higher than the ones located at the height of $0.25 \mathrm{~m}$. These results indicate that the efficiencies of reduction of radiation exposures would be different when resident is standing or lying.

It should be noted that the calculations of the shielding factors for external exposures due to deposited radionuclides were made on the assumption that exposures occurred by only the radionuclides deposited on the ground surface. Jacob and Meckbach[3] indicated that "effective source strength" of different urban

a This value is given by the ratio of the intensity of gamma ray emitted from different surfaces contaminated by radioactive cesium to that from a lawn with a dry deposition. 
surfaces. According to their results, contributions of gamma ray emitted from the surface of walls and windows to radiation exposures in the room are not significant. On the other hand, the contribution of gamma ray emitted from the surface of roofs is important to estimate shielding efficiency, since the effective source strength of roofs is in the band of 30-70\%.

In the present study, the calculations were performed based on the data which were gained by surveys on educational facilities, i.e. multistory buildings. The importance of the different surfaces depends on floor number. In particular, the relative importance of the contamination of roofs decrease with decreasing floor number, because photons emitted from radionuclides deposited on roofs are better shielded by the relatively massive ceiling. Therefore, the shielding factors evaluated in the present study provide the findings for a location away from roofs such as the first floor of multi-story building. The results of this study should be interpreted with an attention to this limitation.

Table 3 shows the comparison of the shielding factors of the present study with those of the previous works [4-6]. Burson et al.[4] showed the calculated values of 0.2 or less as the shielding factor for air submersion. The calculations are made for large office or industrial type building without considerations of contributions of windows. Yamaguchi and Minami[5] pointed out that the estimation of the shielding factor for air submersion is largely influenced by gamma ray passing through windows. They suggested that the shielding factors of 0.4 for ferroconcrete houses. This value was calculated on the assumption that the fraction of windows is $20 \%$ for outer surface area of the building.

For the exposures to deposited radionuclides, the shielding factor of 0.05 was proposed by Burson et al.[4]. This value is derived experimentally from fallout radiation in the first floor of 3 or 4-story buildings. Meckbach et al.[6] gave the approximate value of 0.03 as a shielding factor in the first floor of the multistory building. This calculation was made by a monoenergetic gamma source with energy of $0.662 \mathrm{MeV}$.

The estimated values of shielding factors for deposited radionuclides of the present study were greater than those of previous works. As shown in Table 3, the shielding factors vary with the location in the room. Furthermore, estimations of the factors are strongly affected by the window-area of the facilities, as previous works pointed out[5][7] ${ }^{\mathrm{b}}$. To identify the reasons of the differences between the shielding factor of the present study and those of the previous works, further considerations will be needed, taking into account the contributions of contaminated roofs.

\footnotetext{
b Jensen[7] shows data of the fractions of window-area for several European countries. According to this work, the value of $16 \%, 20 \%$ and $25 \%$ was reported for building of French, British and Denmark, respectively.
}

Table 3. Shielding factors of the various locations in the room for air submersion and deposited radionuclides

\begin{tabular}{lccc}
\hline $\begin{array}{c}\text { Exposure pathways and } \\
\text { Location of detector }\end{array}$ & \multicolumn{2}{c}{$\begin{array}{c}\text { Present work } \\
\text { (for } 0.6 \mathrm{MeV} \text { photon) }\end{array}$} & $\begin{array}{c}\text { Previous } \\
\text { works }\end{array}$ \\
\cline { 2 - 3 } & $0.25 \mathrm{~m}^{*}$ & $1.0 \mathrm{~m} *$ & \\
\hline Air submersion & & & \\
\hline $\begin{array}{l}\text { The center of a room } \\
\text { Window side }\end{array}$ & 0.29 & 0.27 & $\sim 0.4^{[4],[5]}$ \\
$\quad$ Deposited radionuclides & & 0.40 & \\
$\quad \begin{array}{l}\text { The center of a room } \\
\text { Window side }\end{array}$ & 0.10 & 0.16 & $0.03 \sim$ \\
& 0.20 & 0.33 & $0.05^{[4],[6]}$ \\
\hline
\end{tabular}

* The height of detector location from the floor (see Fig. 1).

\subsection{Dependence of Shielding factors on Photon energy}

The dependence of the shielding factors on the photon energy is shown in Figure 3. The source energy is changed from 0.1 to $1.5 \mathrm{MeV}$, to analyze its relation with the shielding factors. The energy dependences show different characteristics according to the photon source. In the case of the air submersion, the shielding factors increase with increasing the photon energy. On the other hand, shielding factors remains almost constant to the variations of source energy above $0.2 \mathrm{MeV}$ for the deposited radionuclides.

The both dependences are accounted for by the mass thickness of the materials photons pass through when they come into the room. In the case of air submersion, photons pass through the walls and the roofs, whose mass thickness is high enough for an energy dependence to be observable. Meanwhile, the photons from deposited radionuclides pass through the walls and the windows. The mass thickness of the latter is so low that even the low energy photons penetrate into the room. This result indicates that the efficiencies of reduction of radiation exposures are strongly affected by the windows, whose mass thickness is lower than those of walls and roofs.

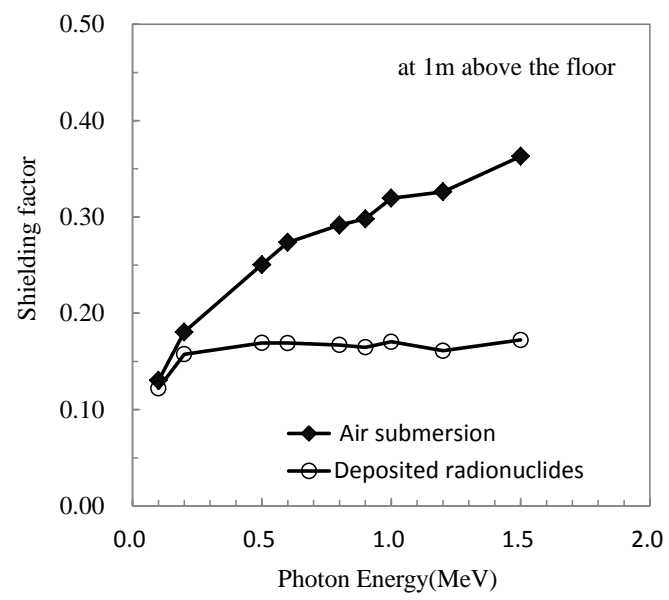

Figure 3. Shielding factors for the detectors at the height of 1 $\mathrm{m}$ above the floor at the center of the room as a function of photon energy for air submersion and radionuclides deposited onto the ground. 
Above discussion on the shielding factors for deposited radionuclides is based on the considerations without contributions from radionuclides deposited on roofs. Therefore, this preliminary estimation cannot provide findings with regard to the dependences of shielding factors on photon energy for upper floors of multi-story buildings and wooden frame residences.

\section{Conclusion}

The surveys on building materials and structures were performed for the evacuation facilities actually used in the Prefectural Regional Emergency Prevention Plan of Shimane Prefecture. On the basis of the survey results, preliminary evaluations of the shielding factors of the facilities were performed. The resulting shielding factors for the radiation due to air submersion were almost within the range of the results of the previous works. In the case of deposited radionuclides, the shielding factors were greater than that of the previous works. This preliminary evaluation was performed taking into account only the contribution from radionuclides deposited on the ground. To explain the differences between shielding factors of the present study and that of previous works, further considerations will be needed, taking into account contributions of contaminated roofs.

The shielding factors for air submersion at the center of the room increase as the photon energies increases. On the other hand, the obvious energy dependence of the shielding factors for deposited radionuclides is not observed unlike the shielding factor for air submersion. The differences between the energy dependence of shielding factors for air submersion and for deposited radionuclides are caused by the difference of the mass thickness of the materials in the penetration pathway.

It should be noted that the calculations of the shielding factors for deposited radionuclides were made with considerations of contributions from the ground surface only. To estimate shielding factors for various locations, further considerations will be needed, taking into account the contributions of contaminated roofs.

\section{Acknowledgements}

This research project had been conducted under the contract with Shimane Prefecture.

\section{References}

[1] X-5 Monte Carlo Team, MCNP - A General Monte Carlo N-Particle Transport Code, Version 5 Volume I: Overview and Theory, LA-UR-03-1987, Los Alamos, (2003).

[2] M. C. White, Photoatomic Data Library MCPLIB04: A New Photoatomic Library Based On Data from ENDF/B-VI Release 8, LA-UR-03-1019, Los Alamos, (2003).

[3] P. Jacob and R. Meckbach, Shielding factors and external dose evaluation, Raidat. Prot. Dosim. 21 1/3, (1987), pp.79-85.

[4] Z.G. Burson and A.E. Profio, Structure shielding in reactor accidents, Health Phys. 33, (1977), pp.287-299.

[5] Y. Yamaguchi and K. Minami, Radiation shielding effect of typical residential houses in Japan in reactor accidents, Nihon-Hokenbutsuri-Gakkai Shi (Jpn. J. Health Phys.) 24, (1989), pp.11-17. [in Japanese]

[6] R. Meckbach, P. Jacob and H. G. Paretzke, Shielding of gamma radiation by typical European houses, Nulc. Instrum. Meth. Phys. Res. A255, (1987), pp.160-164.

[7] P. H. Jensen, Calculated shielding factors for selected European houses, Ris $\phi-M-2474$, (1984) 